\title{
Allozyme variability in sexual and parthenogenetic freshwater planarians: evidence for polyphyletic origin of parthenogenetic lineages through hybridization with coexisting sexuals
}

\author{
NORBERT PONGRATZ*, TIMOTHY F. SHARBEL, LEO W. BEUKEBOOM $+\&$ \\ NICO K. MICHIELS \\ Arbeitsgruppe Michiels, Max-Planck-Institut für Verhaltensphysiologie, Seewiesen, PO Box 1564, D-82305 \\ Starnberg, Germany
}

\begin{abstract}
In Dugesia polychroa, a hermaphroditic planarian, diploid sexual and polyploid pseudogamous parthenogenetic forms exist in separate populations and in sympatry. Parthenogens produce viable, haploid sperm that are exchanged between two individuals during copulation and trigger sperm-dependent parthenogenetic egg development. In crossing experiments, parthenogens can fertilize the eggs of sexuals, occasionally initiating the origin of new polyploid parthenogenetic lineages. We present an allozyme study of genetic variation in both separate and mixed populations, in which multilocus genotypes defined by seven loci were used to characterize parthenogenetic lineages. Purely parthenogenetic populations were found to be composed of genotypically different lineages. In mixed populations, the allelic variation of parthenogens is similar to that of the coexisting sexuals. The observed genotypic diversity suggests that parthenogens from mixed populations are of polyphyletic origin. We propose that, in natural populations, hybridization between sympatric sexuals and parthenogens leads to the appearance of new, genetically diverse parthenogenetic lineages.
\end{abstract}

Keywords: allozyme, clonal diversity, Dugesia, hybridization, planarian, pseudogamous parthenogenesis.

\section{Introduction}

In studies of parthenogens, high genotypic diversity among parthenogenetic lineages is often interpreted as evidence for multiple lineage origins (Lokki et al., 1975; Parker, 1979), with each a reflection of the genetic variation found in their sexually reproducing progenitors. Additionally, in populations in which both sexual and parthenogenetic biotypes of the same species coexist, the question regarding reproductive isolation between the two arises. Responding to the observation that parthenogens are sometimes unable to compete in sympatry with their sexual progenitors (Cuellar, 1977), Lynch (1984) proposed that hybridization between the two biotypes nega-

*Correspondence. E-mail: pongratz@mpi-seewiesen.mpg.de $\dagger$ Current address: Institute for Evolutionary and Ecological Sciences, University of Leiden, PO Box 9516, NL-2300 RA Leiden, The Netherlands. tively affects the successful establishment of parthenogenetic lineages. Nevertheless, species with overlapping distributions of sexual and parthenogenetic forms are known (Suomalainen et al., 1987). In species with separate sexes (gonochorists), parthenogenetic populations are unisexual, and reproductive interactions, if any, occur only between sexual males and parthenogenetic females. In this regard, hermaphrodites differ markedly from species with separate sexes. In hermaphroditic species, parthenogenetic egg development is not necessarily concomitant with the loss of male function and, thus, parthenogens could possibly transmit their genes via sperm when they mate with sexuals (Benazzi Lentati, 1970; Christensen, 1980).

Dugesia polychroa is a hermaphroditic flatworm found throughout Europe, and sexuals and parthenogens exist in allopatry or in sympatry. Purely parthenogenetic populations are found north of the 
Alps, whereas sexuals seem to have the centre of their distribution south of the Alps, in middle and northern Italy (Beukeboom et al., 1996). Dugesia polychroa is incapable of self-fertilization and, thus, sperm must be exchanged between individuals during copulation, a requirement that holds for both sexuals and parthenogens. Parthenogens are pseudogamous (i.e. sperm dependent), meaning that zygote development is initiated by fertilization with sperm, but the sperm's chromosome set is subsequently eliminated and makes no genetic contribution to the developing embryo (Benazzi Lentati, 1970). Thus, the term parthenogen refers to hermaphrodites in which the female function is parthenogenetic but relies on sperm from the male function of conspecifics. Even though parthenogens are polyploid (usually triploid), they produce viable haploid sperm. Under laboratory conditions, it has been shown that parthenogens are able to fertilize the eggs of (diploid) sexual mating partners. The resulting hybrids can have triploid parthenogenetic offspring when unreduced, diploid eggs occasionally produced by hybrids are fertilized (Benazzi Lentati, 1970). This means that new parthenogenetic lineages can arise through syngamy.
In naturally occurring mixed populations, hybridization between sexuals and parthenogens may be a continual source of new parthenogenetic lineages. Syngamy, as a mechanism of origin, is expected to be manifested by increased genetic variability among parthenogens relative to those undergoing change via mutational processes only. It would also permit genetic exchange between sexual and parthenogenetic lineages, thus precluding their independent evolution.

Here, an allozyme study of genetic variation in pure and mixed populations of $D$. polychroa is presented. We expected that coexisting sexuals and parthenogens would share similar enzyme polymorphisms and, in addition, that multiple origins of new clones should be reflected in different multilocus genotypes among parthenogens.

\section{Materials and methods}

Between February and May 1996, D. polychroa were collected from 15 different localities in Europe. On a broad geographical scale, the sample sites can be assigned to five different regions (Table 1). Dugesia lugubris, a karyotypically different diploid species

Table 1 Sampling localities where Dugesia polychroa were collected for this study

\begin{tabular}{|c|c|c|}
\hline Code & Region/locality & Habitat \\
\hline \multicolumn{3}{|c|}{ The Netherlands } \\
\hline N1 & De Vecht, Nederhorst den Berg & Stream \\
\hline D.1. & Nieuwe Keverdijkse Polder, Weesp (D. lugubris) & Ditch \\
\hline \multicolumn{3}{|c|}{ Southern Germany/Bavaria } \\
\hline N2 & Ammersee & Lake \\
\hline N3 & Isar, Munich & Stream \\
\hline N4 & Chiemsee, near Chieming & Lake \\
\hline \multicolumn{3}{|c|}{ Northern Italy } \\
\hline $\mathrm{C} 1$ & Lago di Caldonazzo (C11-C18)* & Lake \\
\hline $\mathrm{C} 2$ & Lago di Levico & Lake \\
\hline $\mathrm{C} 3$ & Lago di Toblino & Lake \\
\hline $\mathrm{C} 4$ & Sarca, near Arco & Stream \\
\hline $\mathrm{C} 5$ & Lago di Garda & Lake \\
\hline \multicolumn{3}{|c|}{ Surroundings of Pisa (Toscana, Italy) } \\
\hline P1 & 'La Fattoria II' & Ditch \\
\hline P2 & Vorno & Stream \\
\hline P3 & San Lorenzo a Vàccoli & Stream \\
\hline \multicolumn{3}{|c|}{ Surroundings of Lago Trasimeno (Italy) } \\
\hline $\mathrm{T} 1$ & Near Macchie & Stream \\
\hline $\mathrm{T} 2$ & Near Castiglione & Stream \\
\hline $\mathrm{T} 3$ & Lago di Chiusi & Lake \\
\hline
\end{tabular}

*For the exact position of C11-C18 within Lago di Caldonazzo, see Fig. 1. 


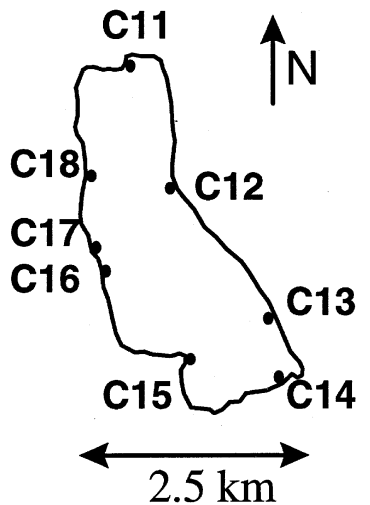

Fig. 1 Location of sampling sites at Lago di Caldonazzo, Italy.

that does not interbreed with $D$. polychroa (Benazzi, 1982), was collected from one locality in the Netherlands for use as an outgroup in our subsequent phylogenetic analyses. In Lago di Caldonazzo, Italy (C1), where both sexuals and parthenogens occur, eight different sites around the shore were sampled for a more detailed analysis of a mixed population (C11-C18, Fig. 1). Live worms were transported to the laboratory in brown plastic pots, where they were maintained at $4^{\circ} \mathrm{C}$. All animals were starved for at least 7 days before karyological and electrophoretic procedures.

\section{Karyology}

In order to distinguish diploid sexuals from polyploid parthenogens, chromosome counts were carried out for each individual. A protocol (modified from Redi et al., 1982; Beukeboom et al., 1996) for preparing chromosomes from regenerated blastemas on freshly cut tail-tips (approximately $3 \mathrm{~mm}$ ) was used, extending colchicine treatment to $7 \mathrm{~h}$. Karyotypes were determined from metaphase nuclei.

\section{Electrophoresis}

Whole worms were frozen in $30 \mu \mathrm{L}$ of extraction buffer $(0.01 \mathrm{~m}$ Tris, $1 \mathrm{~mm}$ EDTA, $1 \mathrm{~mm}$ dithiothreitol, pH 7; Novak et al., 1989) in Eppendorf tubes at $-80^{\circ} \mathrm{C}$. Before using the samples for electrophoresis, the worms were thawed and homogenized, and the tubes were centrifuged for $5 \mathrm{~min}(16434 \mathrm{~g})$ at $4^{\circ} \mathrm{C}$. An initial screening of 19 enzyme systems (see Appendix) resulted in eight reliably resolved presumptive enzyme loci (Table 2). Three different gel and tray buffer systems (Murphy et al., 1990) were used for $12 \%$ starch gel electro-
Table 2 Buffer conditions used for starch gel electrophoresis of the six enzyme systems analysed in this study

\begin{tabular}{ll}
\hline Enzyme (locus) & Buffer \\
\hline Alanine aminotransferase (Alat) & TED 9.6* \\
Aspartate aminotransferase (Aat-1, Aat-2) & AC $6.1 \dagger$ \\
Glucose-6-phosphate isomerase $($ Gpi) & TED 9.6* \\
Glycerol-3-phosphate dehydrogenase $(G 3 p d h)$ & TC $8.0 \ddagger$ \\
L-Iditol dehydrogenase (Iddh) & TC $8.0 \ddagger$ \\
Isocitrate dehydrogenase $(I d h-1, I d h-2)$ & TC $8.0 \ddagger$ \\
\hline
\end{tabular}

*TED 9.6, Tris-EDTA, pH 9.6. Electrode: 0.1 м Tris, $4.5 \mathrm{~mm}$ disodium-EDTA, adjusted to $\mathrm{pH}$ 9.6; gel: 1:9 dilution of electrode buffer.

$\dagger$ AC 6.1, amine-citrate, $\mathrm{pH}$ 6.1. Electrode: $0.04 \mathrm{~m}$ citric acid, adjusted to $\mathrm{pH} 6.1$ with $N$-aminopropylmorpholine; gel: 1:19 dilution of electrode buffer.

¥C 8.0, Tris-citrate, $\mathrm{pH} 8.0$. Electrode: $0.687 \mathrm{~m}$ Tris, $0.157 \mathrm{~m}$ citric acid, adjusted to $\mathrm{pH}$ 8.0; gel: 1:29 dilution of electrode buffer.

phoresis (Table 2). Gels were run overnight for 14-16 h. Staining procedures were used as described by Murphy et al. (1990), with a slight modification for Iddh, where activity was enhanced by adding $2 \mathrm{~mL}$ of $0.1 \mathrm{M} \mathrm{MgCl}_{2}$ to the staining solution.

\section{Analysis of electrophoretic data}

Allele frequencies were calculated for each population sampled, separating sexual and parthenogenetic biotypes. In sample sites containing both biotypes, individuals whose karyotypes could not be determined reliably were excluded from further analyses. For polyploid parthenogenetic populations, allele frequencies were calculated as the mean of individual frequencies for each allele. Individual frequencies for both alleles were set equal to 0.5 , when it was not possible to detect a dosage pattern from the band intensities that would indicate which allele was present twice in a triploid heterozygous genotype with two different alleles; from here on, these will be referred to as diallelic heterozygotes. Average heterozygosity for each locus and population was estimated from direct counts.

In addition, genotype frequencies were calculated for parthenogenetic (sub)populations. At Iddh and $G p i$, all diallelic genotypes with the same two alleles were pooled in one class when it was not possible to resolve band intensities for all individuals of a sample. A model by Tomiuk \& Loeschcke (1991) was used for estimating pairwise genetic identity values $(I)$ between 17 populations, including the $D$. 
lugubris population as outgroup, from single-locus genotype frequencies. The model allows pooling of diallelic heterozygotes that share both alleles, and direct formulae are provided for the maximum likelihood estimators for diploid and triploid populations (Tomiuk \& Loeschcke, 1996). Parthenogens from populations P1-P3, which are composed largely of tetraploids, were excluded from this analysis. Sexuals and parthenogens from $\mathrm{C} 1$ were treated as separate populations. Pairwise genetic distances $(D)$ were calculated from genetic identity values using the standard formula $D=-\ln I$, and the resultant pairwise genetic distance matrix was used for UPGMA clustering (PHYLIP 3.5c, Felsenstein, 1993). Genotype distributions in sexual populations were tested for deviations from Hardy-Weinberg equilibrium with an exact $\chi^{2}$-test for goodness of fit, using statхаст 3 (Cytel Software).

\section{Genotypic diversity of parthenogens}

Genetic diversity of a parthenogenetic population can be defined as the number of genetically different clonal lineages that can be detected. As pseudogamous parthenogens reproduce clonally via the female function to produce genetically identical offspring, the number of multilocus genotypes gives a minimum estimate for the number of genetically different clones present in a population. We did not know whether or how tetraploids arise from triploids (or vice versa) and, thus, excluded all tetraploid individuals from the analysis of mainly triploid populations (N1-N4 and $\mathrm{C} 11-\mathrm{C} 18)$.

For the frequency distribution of the five most common genotypes among parthenogens from samples C11-C18, a Fisher-Monte-Carlo test was performed using SтAтХАCт 3 to test whether the clones were equally distributed among the eight samples taken from around the shore.

\section{Results}

\section{Biotype composition of natural populations}

North of the Alps, mostly triploid and no diploid individuals were identified (N1-N4). All sample sites from Italy contained diploid animals and, of these, seven contained no polyploid individuals (T1-T3, C2-C5; Table 3). Hereafter these latter sites are referred to as pure sexual populations. Parthenogens were mainly tetraploid in the surroundings of Pisa. The eight samples from Lago di Caldonazzo (C1, C11-C18) contained diploids and mainly triploids in different ratios. Our samples C15, C16 and C18 contained only triploid and tetraploid individuals, but recent studies have documented diploids at these sites also (unpubl. data; Weinzierl, 1996) and, thus, they were considered as mixed populations.

\section{Allozyme variability}

Six of the seven allozyme loci for which data are available for all populations showed interpopulational polymorphisms. Allele frequencies for all populations are given in the Appendix. Idh-1 was excluded from further analyses because complete data were not available for all populations because of uninterpretable banding patterns. At Gpi and $I d d h$, dosage patterns that would specify which allele was present twice in triploid diallelic heterozygotes could not be scored reliably.

Average heterozygosity was similar in pure sexual (T1-T3, C2-C5) and pure parthenogenetic (N1-N4) populations, but was about 2.5 times higher in the parthenogenetic population from Lago di Caldonazzo ( $\mathrm{C} 1$; see Appendix). Sexual populations showed no significant deviation from HardyWeinberg equilibrium, with one exception ( $\mathrm{C} 4$ at $G p i, P=0.037)$.

Table 3 Absolute numbers of diploid, triploid and tetraploid individuals in samples of Dugesia polychroa from different localities $(N=$ sample size $)$

\begin{tabular}{lrrrr}
\hline Locality & $N$ & $2 n$ & $3 n$ & $4 n$ \\
\hline N1 & 20 & 0 & 18 & 2 \\
N2 & 31 & 0 & 26 & 5 \\
N3 & 16 & 0 & 12 & 4 \\
N4 & 37 & 0 & 37 & 0 \\
C1 & & & & \\
C11 & 20 & 2 & 18 & 0 \\
C12 & 23 & 20 & 3 & 0 \\
C13 & 22 & 1 & 20 & 1 \\
C14 & 17 & 4 & 13 & 0 \\
C15 & 21 & 0 & 20 & 1 \\
C16 & 17 & 0 & 17 & 0 \\
C17 & 21 & 11 & 10 & 0 \\
C18 & 17 & 0 & 17 & 0 \\
C1 (total) & 158 & 38 & 118 & 2 \\
C2 & 20 & 20 & 0 & 0 \\
C3 & 20 & 20 & 0 & 0 \\
C4 & 24 & 24 & 0 & 0 \\
C5 & 24 & 24 & 0 & 0 \\
P1 & 29 & 20 & 4 & 5 \\
P2 & 40 & 26 & 0 & 14 \\
P3 & 43 & 10 & 0 & 33 \\
T1 & 15 & 15 & 0 & 0 \\
T2 & 21 & 21 & 0 & 0 \\
T3 & 12 & 12 & 0 & 0 \\
\hline
\end{tabular}


Pairwise genetic identity and distance values between populations calculated after Tomiuk \& Loeschcke $(1991,1996)$ are listed in Table 4. Within regions, genetic distances between populations were relatively small, ranging from 0 to 0.074 , whereas the values were on average (0.15) larger between populations from different regions. Genetic distances between populations of $D$. polychroa and the population of D. lugubris ranged between 1.03 and 1.39 . The UPGMA phenogram (Fig. 2) derived from genetic distances points out the genetic similarity of geographically close populations. Triploids collected south of the Alps (C1) appeared in a different cluster from those from localities in the Netherlands and Germany (N1-N4).

In pure parthenogenetic populations, between two and four multilocus genotypes were found among triploids (Table 5). In the mixed populations P1-P3, all the alleles found in tetraploids (and the rare triploids) were also found in the diploids, and no allele specific only to sexuals or parthenogens was detected. The diploid sexuals showed no deviation from Hardy-Weinberg equilibrium. With respect to multilocus genotypes, only a part of the genotypic variability found in coexisting sexuals was represented in parthenogenetic tetraploids, although the same alleles are present in both populations. Each of the four triploid individuals from population $\mathrm{P} 1$ had a different Alat/Gpi genotype: $B B B / A$ ? $B$, $B B B / A B C, \quad B B B / B B B$ and $B B D / A ? C \quad(A ? B$, $A ? C=$ unresolved diallelic genotypes).
In population $\mathrm{C} 1$ (Lago di Caldonazzo), sexuals and parthenogens share all detected alleles, except for alleles $A$ at $G 3 p d h$ and $D$ at Alat, which were specific to parthenogens. Genetic identity between sexuals and parthenogens is relatively high $(I=0.995$, i.e. there is no higher pairwise genetic identity value with one of the other populations studied for both the diploid and triploid populations from $\mathrm{C} 1$ ), and this is reflected in the UPGMA phenogram (Fig. 2).

In population $\mathrm{C} 1,22$ different multilocus genotypes among 116 triploid individuals were resolved by six variable enzyme loci (Table 6). The distribution of the five most common genotypes differs between sites $(P<0.0001$; Fisher's exact test, MonteCarlo sampling).

\section{Discussion}

Independent origins of parthenogenetic populations

Polyploid, pseudogamous, parthenogenetic D. polychroa occur over a wide geographical range in Europe, in pure parthenogenetic populations as well as in sympatry with conspecific diploid sexuals. When geographically isolated parthenogenetic populations are genetically more closely related to coexisting sexuals than to each other, independent endemic origins of parthenogenetic clones is the most parsimonious explanation (Quattro et al., 1991, 1992) and, thus, genotypes of parthenogenetic clones

Table 4 Genetic identity $I$ after Tomiuk \& Loeschcke $(1991,1996)$ (above diagonal) and genetic distance $D=-\ln I$ (below diagonal) for 16 diploid and triploid populations of Dugesia polychroa and one population of $D$. lugubris (D.1.)

\begin{tabular}{|c|c|c|c|c|c|c|c|c|c|c|c|c|c|c|c|c|c|}
\hline & N1 & N2 & N3 & N4 & $\mathrm{C} 12 n$ & C1 3n & $\mathrm{C} 2$ & C3 & $\mathrm{C} 4$ & C5 & P1 & $\mathrm{P} 2$ & P3 & $\mathrm{T} 1$ & $\mathrm{~T} 2$ & T3 & D.1. \\
\hline N1 & & & 0.977 & 0.966 & 961 & 0.906 & & & & & & & & & & & \\
\hline $\mathrm{N} 2$ & 0.003 & & 0.972 & 1.000 & .931 & 0.883 & 0.945 & .944 & 0.944 & 0.934 & 0.818 & 0.816 & 0.815 & 0.818 & 0.813 & 0.818 & 0.338 \\
\hline N3 & 0.023 & 0.028 & & 0.945 & 0.951 & 0.916 & 0.965 & 0.963 & 0.963 & 0.987 & 0.797 & 0.818 & 0.824 & 0.675 & 0.689 & 0.704 & 0.345 \\
\hline N4 & 0.035 & 0.000 & 0.057 & & 0.952 & 0.894 & 0.967 & 0.965 & 0.965 & 0.955 & 0.845 & 50 & 0.8 & 0.842 & 0.8 & & 0.345 \\
\hline $\mathrm{C} 12 n$ & 0.040 & 0.071 & 0.050 & 0.049 & & 0.995 & 0.980 & 0.985 & 0.983 & 0.968 & 0.954 & 0.976 & 0.984 & 0.832 & 0.847 & 0.863 & 0.351 \\
\hline $\mathrm{C} 3$ & & & 0.038 & & 0.015 & 0.029 & 0.002 & & 0.996 & & 0.9 & & & & & & 0.356 \\
\hline $\mathrm{C} 4$ & 0.026 & 0.058 & 0.038 & 0.036 & 0.017 & 0.065 & 0.002 & 0.004 & & 0.985 & 0.824 & 0.846 & 0.852 & 0.698 & 0.713 & 0.729 & 0.356 \\
\hline $\mathrm{C} 5$ & & 0.068 & & 0.046 & & & & & & & 0.812 & & 0.8 & & & 18 & 0.351 \\
\hline P1 & 0.201 & 0.201 & 0.227 & 0.168 & 0.047 & 0.048 & 0.191 & 0.033 & 0.194 & 0.208 & & 0.999 & 1.000 & 1.000 & 0.9 & 1.000 & 0.342 \\
\hline $\mathrm{P} 2$ & 0.183 & 0.203 & 0.201 & 0.163 & 0.024 & 0.034 & 0.166 & 0.010 & 0.167 & 0.183 & 0.001 & & 0.998 & 0.998 & 0.991 & 0.998 & 0.301 \\
\hline P3 & 0.178 & 0.205 & 0.194 & 0.192 & 0.016 & 0.029 & 0.158 & 0.004 & 0.160 & 0.176 & 0.000 & 0.002 & & 0.857 & 0.853 & 0.882 & 0.304 \\
\hline D.1. & 1.056 & 1.085 & 1.064 & 1.064 & 1.047 & 1.109 & 1.030 & 1.033 & 1.033 & 1.047 & 1.073 & 1.201 & 1.191 & 1.394 & 1.366 & 1.382 & \\
\hline
\end{tabular}


should consist of alleles that are segregating in the sexual population (Dybdahl \& Lively, 1995). Our data show that sympatric sexual and parthenogenetic populations of $D$. polychroa share the same alleles at
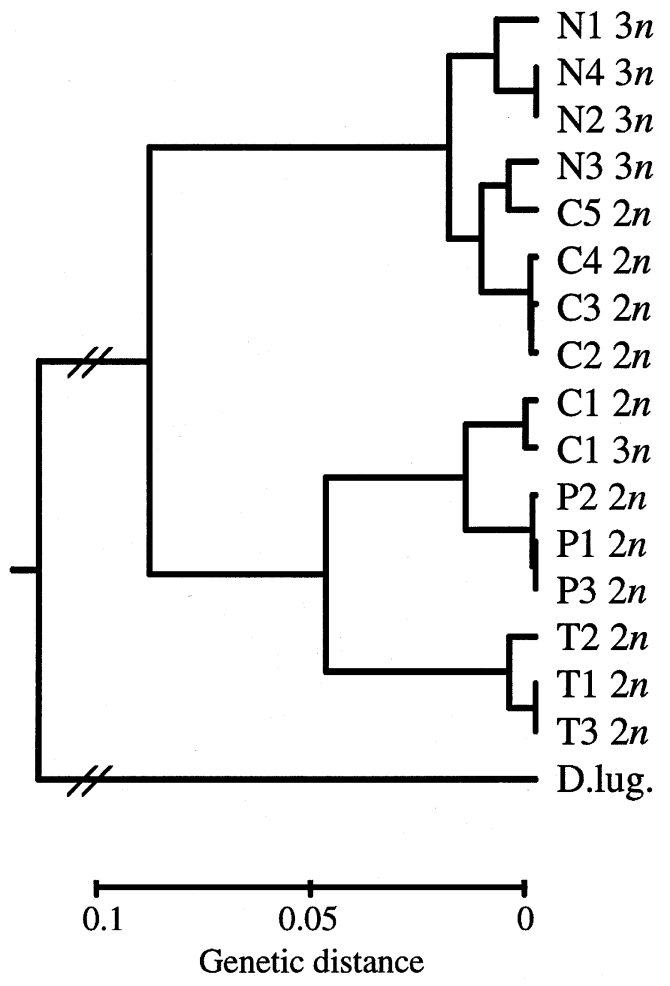

Fig. 2 UPGMA phenogram based on genetic distance between sexual $(2 n)$ and parthenogenetic $(3 n)$ populations of Dugesia polychroa calculated from genotype frequencies (D. lug. = D. lugubris).

Table 5 Absolute numbers of multilocus genotypes of triploid individuals in the samples from purely parthenogenetic populations of Dugesia polychroa

\begin{tabular}{lccccccc}
\hline Alat & $I d d h$ & $G p i$ & G3pdh & $\mathrm{N} 1$ & $\mathrm{~N} 2$ & $\mathrm{~N} 3$ & $\mathrm{~N} 4$ \\
\hline$B B B$ & $A A A$ & $B B B$ & $B B B$ & - & 1 & - & 4 \\
$B B B$ & $A A A$ & $B B C$ & $B B B$ & - & - & - & 33 \\
$B B B$ & $A B$ & $A B$ & $B B B$ & 2 & - & - & - \\
$B B B$ & $A B$ & $B B B$ & $B B B$ & 11 & 11 & 4 & - \\
$B B B$ & $B B B$ & $A B$ & $B B B$ & 3 & - & - & - \\
$B B B$ & $B B B$ & $B B B$ & $A B B$ & - & - & 8 & - \\
$B B B$ & $B B B$ & $B B B$ & $B B B$ & 2 & - & 1 & - \\
$B B D$ & $A B$ & $B B B$ & $B B B$ & - & 3 & - & - \\
$B B D$ & $A B$ & $B B C$ & $B B B$ & - & 2 & - & - \\
\hline
\end{tabular}

(C) The Genetical Society of Great Britain, Heredity, 81, 38-47. all polymorphic loci, and this holds for both the mixed diploid-triploid (C1) and for the mixed diploid-tetraploid (P1-P3) populations. This suggests that parthenogenetic lineages from different regions, namely Toscana (P1-P3) and Northern Italy (C1), have independent origins from within different sexual populations. Polyphyletic origins of parthenogens have been supported previously by the existence and distribution of cytogenetically different parthenogenetic biotypes (Benazzi, 1957; Beukeboom et al., 1996). With allozymes, it was possible to detect differences between triploids occurring north and south of the Alps. The genetic identity index shows that triploids from $\mathrm{C} 1$ are genetically more similar to their sympatric diploids than to triploids from populations N1-N4 (the Netherlands and southern Germany).

\section{Origin of genotypic diversity in triploid lineages}

Parker (1979) mentions three sources of clonal variation in parthenogens: (i) multiple origins from sexual ancestors; (ii) mutation; and (iii) meiotic recombination. Benazzi (1957) described triploid $D$. polychroa from northern Italy and Germany as 'synaptic' biotypes, in which meiosis takes place after endoduplication of the triploid chromosome set, with pairing and subsequent segregation of identical, duplicated copies of the same chromosome. Therefore, only in exceptional cases of multivalent formation or pairing of nonsister homologues will offspring not be clonal but have different genotypes at loci heterozygous in the mother individual.

Mutations may change electromorph charge states at a locus to produce new alleles or silence existing alleles, so that enzyme activity is no longer detectable (Spinella \& Vrijenhoek, 1982). In both cases, new genotypes are similar to their ancestral genotype, differing only at the mutated locus (Lokki et al., 1975). This may be the case in samples from pure parthenogenetic populations, in which between two and four multilocus genotypes were found, with not more than two genotypes per locus per population. As mentioned above, it is not possible to exclude rare events of irregular meiosis in triploids and, thus, mutation may only explain a part of the genotypic variation.

When genotypic diversity among parthenogens cannot be explained by single-step mutations from a common genotype, polyphyletic origins of parthenogenetic lineages is a likely explanation (Lokki et al., 1975). The data from mixed populations P2 and P3 prevent any such inference, as all parthenogens from this site were tetraploid, most of which were diallelic 
Table 6 Absolute numbers of all multilocus genotypes found among triploids from the mixed population $\mathrm{C} 1$ (subpopulations C11-C18) of Dugesia polychroa

\begin{tabular}{lllllllllllllll}
\hline Aat-1 & Alat & $I d d h$ & $I d h-2$ & $G p i$ & $G 3 p d h$ & $\mathrm{C} 11$ & $\mathrm{C} 12$ & $\mathrm{C} 13$ & $\mathrm{C} 14$ & $\mathrm{C} 15$ & $\mathrm{C} 16$ & $\mathrm{C} 17$ & $\mathrm{C} 18$ & $\mathrm{C} 1$ \\
\hline$A B B$ & $B B B$ & $B ? C$ & $B B B$ & $A A A$ & $A B B$ & 1 & - & - & - & - & - & - & - & 1 \\
$A B B$ & $B B B$ & $B ? C$ & $B B B$ & $A ? B$ & $B B B$ & 1 & - & - & - & - & - & - & - & 1 \\
$A B B$ & $B B B$ & $B ? C$ & $B B C$ & $A ? B$ & $B B B$ & 1 & - & - & - & - & - & - & - & 1 \\
$B B B$ & $B B B$ & $B B B$ & $B B B$ & $A A A$ & $B B B$ & 1 & - & - & - & - & - & - & - & 1 \\
$B B B$ & $B B B$ & $B ? C$ & $B B B$ & $A A A$ & $B B B$ & 1 & - & - & - & - & - & - & - & 1 \\
$B B B$ & $B B B$ & $B ? C$ & $B B B$ & $A ? B$ & $A B B$ & 1 & - & - & - & 1 & 2 & 1 & - & 5 \\
$B B B$ & $B B B$ & $B ? C$ & $B B B$ & $A ? B$ & $A B D$ & - & - & - & 6 & 7 & 1 & 7 & - & 21 \\
$B B B$ & $B B B$ & $B ? C$ & $B B B$ & $A ? B$ & $B B B$ & 4 & - & - & - & 6 & 1 & 2 & 5 & 18 \\
$B B B$ & $B B B$ & $B ? C$ & $B B B$ & $A ? B$ & $B B D$ & 3 & - & 2 & - & 1 & 5 & - & - & 11 \\
$B B B$ & $B B B$ & $B ? C$ & $B B B$ & $B B B$ & $A B B$ & - & - & 1 & - & 2 & - & - & - & 3 \\
$B B B$ & $B B B$ & $B ? C$ & $B B B$ & $B B B$ & $B B B$ & - & - & 1 & - & 1 & 1 & - & - & 3 \\
$B B B$ & $B B B$ & $B ? C$ & $B B C$ & $A ? B$ & $A B D$ & - & - & - & 1 & - & - & - & - & 1 \\
$B B B$ & $B B B$ & $B ? C$ & $B B C$ & $A ? B$ & $B B B$ & - & - & - & 1 & 2 & - & - & - & 3 \\
$B B B$ & $B B B$ & $B ? C$ & $B B C$ & $A ? B$ & $B B D$ & 4 & - & 11 & 5 & - & - & - & - & 20 \\
$B B B$ & $B B B$ & $B ? C$ & $B B C$ & $B B B$ & $A B B$ & - & - & - & - & - & 1 & - & - & 1 \\
$B B B$ & $B B B$ & $B ? C$ & $B B C$ & $B B B$ & $B B B$ & - & 1 & - & - & - & - & - & - & 1 \\
$B B B$ & $B B B$ & $B ? C$ & $B B C$ & $B B B$ & $B B D$ & 1 & - & 5 & - & - & - & - & - & 6 \\
$B B B$ & $B B B$ & $C C C$ & $B B B$ & $A ? B$ & $A B D$ & - & - & - & - & - & 2 & - & - & 2 \\
$B B B$ & $B B B$ & $C C C$ & $B B B$ & $B B B$ & $B B B$ & - & 1 & - & - & - & - & - & - & 1 \\
$B B B$ & $B B D$ & $B ? C$ & $B B B$ & $A ? B$ & $B B B$ & - & - & - & - & - & - & - & 12 & 12 \\
$B B B$ & $B B D$ & $B ? C$ & $B B B$ & $B B B$ & $A B D$ & - & 1 & - & - & - & - & - & - & 1 \\
$B B B$ & $B B D$ & $B ? C$ & $B B C$ & $B B B$ & $B B B$ & - & - & - & - & - & 2 & - & - & 2 \\
\hline
\end{tabular}

$A ? B$ and $B ? C$ designate unresolved diallelic genotypes.

heterozygotes at Gpi. As it was not possible to resolve potentially asymmetric banding patterns in order to distinguish between $A A A B, A A B B$ and $A B B B$ genotypes, the number of multilocus genotypes detected might be an underestimate of the true number. The same is true for tetraploids from $\mathrm{P} 1$, although the picture is different for triploids from this site, because they have four different multilocus genotypes that combine all alleles segregating in their coexisting sexual population.

The strongest evidence supporting multiple origins of triploids comes from the detailed study of population $\mathrm{C} 1$, in which 22 different multilocus genotypes were identified among 116 triploid individuals. Their distribution differs between sites, showing that the parthenogenetic population is structured. This can result from genetic drift or from ecological differences between clones (Vrijenhoek, 1990). Although rare recombinational events and mutation within lineages may account for some of the variation, the most parsimonious explanation for this pattern is polyphyletic origins of triploid parthenogens from coexisting sexuals. Clones of polyphyletic origins in mixed populations, inferred from high allozyme genotypic diversity, have also been reported from the New Zealand freshwater snail Potamopyrgus antipodarum (Dybdahl \& Lively, 1996).

\section{Hybridization of sexuals and parthenogens}

Polyphyletic origins of parthenogenetic D. polychroa are supported further by the results of earlier studies by Benazzi \& Benazzi Lentati (1992), which suggest that sexual and parthenogenetic $D$. polychroa can hybridize. From laboratory crosses, it has been shown that parthenogens can occasionally fertilize eggs of sexuals and that the resulting hybrids may be a source of new parthenogenetic lineages (overview in Benazzi Lentati, 1970). This is further supported by the fact that the traits determining the cytogenetic processes underlying sperm-dependent parthenogenesis in D. polychroa appear to be genetically transmitted (Benazzi \& Benazzi Lentati, 1992). For example, two of them, namely the production of unreduced eggs and the elimination of the paternal chromosome set from a fertilized egg, have been shown to be inherited independently. In addition, Weinzierl (1996) has shown that diploid D. polychroa collected from a natural, mixed population can occasionally produce triploid offspring, although it 
was not determined whether those triploids reproduced parthenogenetically.

Our allozyme data provide further evidence for the hypothesis that, in natural populations of $D$. polychroa, sexuals and parthenogens can hybridize rather than exist in complete reproductive isolation. Gene flow from parthenogens back to the ancestral sexual population should have homogenizing effects on the two gene pools, minimizing divergence between sexuals and parthenogens, because new alleles arising in one of the two biotypes by mutation will be transmitted to the other one (Menken et al., 1995). Population C1 contained two rare alleles (Alat-D, G3pdh-A) in triploids $(n=116)$ but not in diploids $(n=37)$ of $\mathrm{C} 1$, although this could be attributed to differences in sample size. Parthenogens (C1) had a high number of heterozygotes at some loci. Their allele frequencies were thus close to 0.5 , whereas sexuals showed a different pattern of variability, namely one common allele that is present at high frequency and one rare allele. Analysis of a larger sample $(n=117)$ from $\mathrm{C} 17$ at four loci confirmed this result (unpubl. data). This may mean that gene flow from parthenogens to sexuals, or at least survival or fitness of hybrids, is restricted, so that differences in allele frequencies would be maintained. These hypotheses seem plausible, insomuch as the constant transmission of parthenogenetic genes to sexuals would be expected to result in the fixation of parthenogenesis (Jaenike \& Selander, 1979), although hybridization of sexuals and parthenogens and genetic exchange between them can influence their coexistence in different ways: on the one hand, hybridization of newly arisen parthenogens and conspecific sexuals may prevent successful establishment of parthenogenetic lineages (Lynch, 1984) and, on the other hand, the cost of sex in hermaphrodites is higher if parthenogens can sire parthenogenetic offspring in future generations via their male function (Joshi \& Moody, 1995; Mogie, 1996). In addition, under models that explain the benefits of sexual reproduction by the production of variable offspring (reviewed in Bell, 1982; Case \& Taper, 1986; Michod \& Levin, 1988), high genetic diversity among parthenogens from mixed populations may be advantageous relative to their coexisting sexuals.

\section{Conclusions}

Within pure parthenogenetic populations, genetically different lineages seem to be of monophyletic origin. South of the Alps, parthenogenetic D. polychroa occur in mixed populations, where they are genetically more similar to their sympatric sexual conspecifics than to allopatric parthenogens. This suggests that parthenogenetic lineages have arisen several times independently from at least two different ancestral sexual populations. In addition, the allozyme data revealed polyphyletic origins of parthenogenetic lineages within mixed populations, a lineage being defined by a particular multilocus genotype. We propose that new lineages arise through hybridization between parthenogens and sexuals, resulting in higher genotypic diversity among parthenogenetic lineages in mixed populations.

\section{Acknow ledgements}

We thank Julie Zeitlinger and Martin Storhas for help in collecting flatworms, Rudolfine Illmensee for technical support in the laboratory, Professor Wilfried Gabriel (LMU München), Andrea Streng and Rolf Weinzierl for helpful discussions, and Letizia Gerace, Jaco Greeff and Mike Landolfa for comments on earlier drafts of the manuscript.

\section{References}

BELl, G. 1982. The Masterpiece of Nature: The Evolution and Genetics of Sexuality. University of California Press, Berkeley, CA.

BENAZZI, M. 1957. Cariologia di Dugesia lugubris (Schmidt) (Tricladida Paludicola). Caryologia, 10, 276-303.

BENAZZI, M. 1982. Speciation events evidenced in Turbellaria. In: Barigozzi, C. (ed.) Mechanisms of Speciation. Progress in Clinical and Biological Research, vol. 96, pp. 307-344. Alan R. Liss Inc., New York.

BENAZZI, M. AND BENAZZI LENTATI, G. 1992. Pseudogamy (gynogenesis) in planarians: annotations some forty years on. In: Dallai, R. (ed.) Sex - Origin and Evolution. Selected Symposia Monographs U.Z.I., vol. 6, pp. 87-102. Mucchi, Modena.

BENAZZI LENTATI, G. 1970. Gametogenesis and egg fertilization in planarians. Int. Rev. Cytol., 27, 101-179.

BEUKEBOOM, L. W., WEINZIERL, R. P., REED, K. M. AND MICHIELS, N. K. 1996. Distribution and origin of chromosomal races in the freshwater planarian Dugesia polychroa (Turbellaria: Tricladida). Hereditas, 124, 7-15.

CASE, T. J. AND TAPER, M. L. 1986. On the coexistence and evolution of asexual and sexual competitors. Evolution, 40, 366-387.

CHRISTENSEN, B. 1980. Constant differential distribution of genetic variants in polyploid parthenogenetic forms of Lumbricillus lineatus (Enchytraeidae, Oligochaeta). Hereditas, 92, 193-198.

Cuellar, o. 1977. Animal parthenogenesis. Science, 197, 837-843.

DYBDAHL, M. F. AND LIVELY, C. M. 1995. Diverse, endemic and polyphyletic clones in mixed populations of a fresh- 
water snail (Potamopyrgus antipodarum). J. Evol. Biol., 8, 385-398.

FElsenstein, J. 1993. Phylogeny Inference Package (PHYLIP), version 3.5c. Department of Genetics, University of Washington, Seattle.

JAENIKE, J. AND SELANDER, R. K. 1979. Evolution and ecology of parthenogenesis in earthworms. Am. Zool., 19, 729-737.

JOSHI, A. AND MOODY, M. E. 1995. Male gamete output of asexuals and the dynamics of populations polymorphic for reproductive mode. J. Theor. Biol., 174, 189-197.

LOKKI, J., SUOMALAINEN, E., SAURA, A. AND LANKINEN, P. 1975. Genetic polymorphism and evolution in parthenogenetic animals. II. Diploid and polyploid Solenobia triquetrella (Lepidoptera: Psychidae). Genetics, 79, 513-525.

LYNCH, M. 1984. Destabilizing hybridization, generalpurpose genotypes and geographic parthenogenesis. $Q$. Rev. Biol., 59, 257-290.

MENKEN, S. B. J., SMIT, E. AND DEN NIJS, J. C. M. 1995. Genetical population structure in plants: gene flow between dipoid sexual and triploid asexual dandelions (Taraxacum section Ruderalia). Evolution, 49, 1108-1118.

MICHOD, R. E. AND LEVIN, B. R. (eds) 1988. The Evolution of Sex. Sinauer Associates, Sunderland, MA.

MOGIE, M. 1996. Is there a cost of sex in hermaphrodites? Naturwissenschaften, 83, 225-226.

MURPHY, R. W., SITES, J. W., JR, BUTH, D. G. AND HAUFLER, C. H. 1990. Proteins I: isozyme electrophoresis. In: Hillis, D. M. and Moritz, C. (eds) Molecular Systematics, pp. 45-126. Sinauer Associates, Sunderland, MA.

NOVAK, M., TAYLOR, R. W. AND PIP, E. 1989. Interspecific variation in isozyme patterns in four Hymenolepis species (Cestoda). Can. J. Zool., 67, 2052-2055.

PARKER, E. D. J. 1979. Ecological implications of clonal diversity in parthenogenetic morphospecies. Am. Zool., 19, 753-762.

QUATtro, J. M., AVISE, J. C. AND VRIJENhoeK, R. C. 1991. Molecular evidence for multiple origins of hybridogenetic fish clones (Poeciliidae: Poeciliopsis). Genetics, 127, 391-398.

QUAtTro, J. M., AVISE, J. C. AND VRIJenhoeK, R. C. 1992. Mode of origin and sources of genotypic diversity in triploid gynogenetic fish clones (Poeciliopsis: Poeciliidae). Genetics, 130, 621-628.

Redi, C. A., GARAgnA, s. AND PEllicARI, c. 1982. Chromosome preparation from planarian blastemas: a new procedure suitable for cytogenetic and cytochemical studies. Stain Technol., 57, 190-192.

SPINELlA, D. G. AND VRIJENHOEK, R. C. 1982. Genetic dissection of clonally inherited genomes of Poeciliopsis: II. Investigation of a silent carboxylesterase allele. Genetics, 100, 279-286.

SuOMAlainen, E., SAurA, A. AND LOKKI, J. 1987. Cytology and Evolution in Parthenogenesis. CRC Press, Boca Raton, FL.

TOMIUK, J. AND LOESCHKE, v. 1991. A new measure of genetic identity between populations of sexual and asexual species. Evolution, 45, 1685-1697.

TOMIUK, J. AND LOESCHKE, v. 1996. A maximum-likelihood estimator of the genetic identity between polyploid species. J. Theor. Biol., 179, 51-54.

VRIJENHOEK, R. C. 1990. Genetic diversity and the ecology of asexual populations. In: Wohrmann, K. and Gain, S. K. (eds) Population Biology: Ecological and Evolutionary Viewpoints, pp. 175-197. Springer, Berlin.

WEINZIERL, R. P. 1996. The Maintenance of Sex in an Hermaphrodite. $\mathrm{PhD}$ Thesis. Ludwig-MaximiliansUniversität, München.

\section{Appendix}

Table A1 Enzyme systems initially screened for this study

\begin{tabular}{ll}
\hline Enzyme system & EC code \\
\hline Aconitate hydratase & 4.2 .1 .3 \\
Alanine aminotransferase & 2.6 .1 .2 \\
Alkaline phosphatase & 3.1 .3 .1 \\
Alcohol dehydrogenase & 1.1 .1 .1 \\
Aspartate aminotransferase & 2.6 .1 .1 \\
Dihydrolipoamide dehydrogenase & 1.8 .1 .4 \\
Fumarate hydratase & 4.2 .1 .2 \\
B-Galactosidase & 3.2 .1 .23 \\
Glucose dehydrogenase & 1.1 .1 .118 \\
Glucose-6-phosphate dehydrogenase & 1.1 .1 .49 \\
Glucose-6-phosphate isomerase & 5.3 .1 .9 \\
Glutamate dehydrogenase & 1.4 .1 .2 \\
Glycerol-3-phosphate dehydrogenase & 1.1 .1 .8 \\
L-Iditol dehydrogenase & 1.1 .1 .14 \\
Isocitrate dehydrogenase & 1.1 .1 .42 \\
Lactate dehydrogenase & 1.1 .1 .27 \\
Malate dehydrogenase & 1.1 .1 .37 \\
Phosphoglucomutase & 5.4 .2 .2 \\
6-Phosphogluconate dehydrogenase & 1.1 .1 .44 \\
\hline
\end{tabular}


Table A2 Allele frequencies at eight allozyme loci and mean heterozygosity $(H)$ over seven loci (Idh-1 excluded) in samples of Dugesia polychroa from different localities (D.1. = D. lugubris)

\begin{tabular}{|c|c|c|c|c|c|c|c|c|c|c|c|c|c|c|c|c|c|c|c|c|}
\hline Locus & $\begin{array}{c}\text { Ploidy } \\
N \\
\text { Allele }\end{array}$ & $\begin{array}{c}\mathrm{N} 1 \\
3 n / 4 n \\
20\end{array}$ & $\begin{array}{c}\mathrm{N} 2 \\
3 n / 4 n \\
18\end{array}$ & $\begin{array}{c}\mathrm{N} 3 \\
3 n / 4 n \\
18\end{array}$ & $\begin{array}{c}\mathrm{N} 4 \\
3 n / 4 n \\
48\end{array}$ & $\begin{array}{l}\mathrm{C} 1 \\
2 n \\
37\end{array}$ & $\begin{array}{c}\mathrm{C} 1 \\
3 n \\
116\end{array}$ & $\begin{array}{l}\mathrm{C} 2 \\
2 n \\
21\end{array}$ & $\begin{array}{l}\mathrm{C} 3 \\
2 n \\
20\end{array}$ & $\begin{array}{l}\mathrm{C} 4 \\
2 n \\
23\end{array}$ & $\begin{array}{l}\text { C5 } \\
2 n \\
24\end{array}$ & $\begin{array}{l}\mathrm{P} 1 \\
2 n \\
18\end{array}$ & $\begin{array}{l}\mathrm{P} 2 \\
2 n \\
26\end{array}$ & $\begin{array}{l}\mathrm{P} 2 \\
4 n \\
14\end{array}$ & $\begin{array}{l}\text { P3 } \\
2 n \\
10\end{array}$ & $\begin{array}{l}\text { P3 } \\
4 n \\
31\end{array}$ & $\begin{array}{l}\text { T1 } \\
2 n \\
15\end{array}$ & $\begin{array}{l}\mathrm{T} 2 \\
2 n \\
24\end{array}$ & $\begin{array}{l}\text { T3 } \\
2 n \\
17\end{array}$ & $\begin{array}{l}\text { D.1. } \\
2 n \\
12\end{array}$ \\
\hline Alat & $\begin{array}{l}A \\
B \\
D\end{array}$ & $\begin{array}{c}0.98 \\
- \\
0.03\end{array}$ & $\begin{array}{c}0.86 \\
- \\
0.14\end{array}$ & $\frac{1}{-}$ & $\frac{1}{-}$ & $\frac{1}{-}$ & $\begin{array}{c}0.96 \\
-\overline{0.04}\end{array}$ & $\frac{1}{-}$ & $\frac{1}{-}$ & $\begin{array}{l}1 \\
-\end{array}$ & $\frac{1}{-}$ & $\begin{array}{l}0.82 \\
- \\
0.18\end{array}$ & $\begin{array}{c}0.92 \\
- \\
0.08\end{array}$ & $\begin{array}{c}0.69 \\
- \\
0.31\end{array}$ & $\begin{array}{c}0.95 \\
- \\
0.05\end{array}$ & $\begin{array}{c}0.98 \\
\overline{0.02}\end{array}$ & $\begin{array}{c}0.8 \\
-\overline{0.2}\end{array}$ & $\begin{array}{l}1 \\
-\end{array}$ & $\begin{array}{c}0.88 \\
- \\
0.12\end{array}$ & $\begin{array}{c}0.21 \\
0.79 \\
-\end{array}$ \\
\hline Aat-2 & $\begin{array}{l}A \\
B\end{array}$ & - & - & - & - & - & - & $\overline{1}$ & - & - & - & - & - & - & - & - & - & $\overline{1}$ & - & 1 \\
\hline Gpi & $\begin{array}{l}A \\
B \\
C \\
D\end{array}$ & $\begin{array}{c}0.13 \\
0.88 \\
- \\
-\end{array}$ & $\begin{array}{c}- \\
0.96 \\
0.04 \\
-\end{array}$ & $\begin{array}{l}- \\
- \\
-\end{array}$ & $\begin{array}{c}-\overline{0.71} \\
0.29 \\
-\end{array}$ & $\begin{array}{c}0.03 \\
0.97 \\
- \\
-\end{array}$ & $\begin{array}{c}0.39 \\
0.61 \\
- \\
-\end{array}$ & $\begin{array}{l}- \\
-\end{array}$ & $\begin{array}{l}- \\
- \\
-\end{array}$ & $\begin{array}{c}0.35 \\
0.65 \\
- \\
-\end{array}$ & $\begin{array}{c}0.23 \\
0.77 \\
- \\
-\end{array}$ & $\begin{array}{c}0.34 \\
0.42 \\
0.24 \\
-\end{array}$ & $\begin{array}{c}0.42 \\
0.54 \\
0.04 \\
-\end{array}$ & $\begin{array}{r}0.5 \\
0.5 \\
- \\
-\end{array}$ & $\begin{array}{r}0.3 \\
0.7 \\
- \\
-\end{array}$ & $\begin{array}{c}0.45 \\
0.55 \\
- \\
-\end{array}$ & $\begin{array}{l}- \\
- \\
-\end{array}$ & $\frac{-}{1}$ & $\begin{array}{c}- \\
0.03 \\
0.97 \\
-\end{array}$ & $\frac{-}{-}$ \\
\hline G3pdh & $\begin{array}{l}A \\
B \\
C \\
D\end{array}$ & $\begin{array}{l}- \\
- \\
-\end{array}$ & $\begin{array}{l}- \\
- \\
-\end{array}$ & $\begin{array}{c}0.36 \\
0.64 \\
- \\
-\end{array}$ & $\begin{array}{l}- \\
- \\
-\end{array}$ & $\begin{array}{c}- \\
0.97 \\
- \\
0.03\end{array}$ & $\begin{array}{c}0.1 \\
0.72 \\
- \\
0.18\end{array}$ & $\begin{array}{l}- \\
-\end{array}$ & $\begin{array}{l}- \\
- \\
-\end{array}$ & $\begin{array}{c}- \\
0.98 \\
- \\
0.02\end{array}$ & $\begin{array}{c}0.15 \\
0.85 \\
- \\
-\end{array}$ & $\frac{1}{-}$ & $\begin{array}{l}1 \\
- \\
-\end{array}$ & $\frac{1}{-}$ & $\begin{array}{l}1 \\
- \\
-\end{array}$ & $\frac{1}{-}$ & $\frac{1}{-}$ & $\frac{1}{-}$ & $\frac{1}{-}$ & $\frac{-}{1}$ \\
\hline$I d d h$ & $\begin{array}{l}A \\
B \\
C\end{array}$ & $\begin{array}{c}0.35 \\
0.65 \\
-\end{array}$ & $\begin{array}{c}0.53 \\
0.47 \\
-\end{array}$ & $\begin{array}{c}0.22 \\
0.78 \\
-\end{array}$ & $\frac{1}{-}$ & $\begin{array}{l}- \\
0.95 \\
0.05\end{array}$ & $\begin{array}{c}- \\
0.49 \\
0.51\end{array}$ & $\frac{-}{1}$ & $\begin{array}{c}- \\
0.98 \\
0.03\end{array}$ & $\begin{array}{l}- \\
-\end{array}$ & $\begin{array}{l}- \\
-\end{array}$ & $\frac{-}{1}$ & - & $\frac{-}{1}$ & - & $\frac{-}{1}$ & $\frac{-}{1}$ & - & - & $\begin{array}{l}- \\
-\end{array}$ \\
\hline$I d h-1$ & $\begin{array}{l}A \\
B \\
C\end{array}$ & $\begin{array}{c}0.23 \\
0.78 \\
-\end{array}$ & - & $\begin{array}{l}- \\
1 \\
-\end{array}$ & - & - & - & $\frac{-}{1}$ & $\begin{array}{l}- \\
1 \\
-\end{array}$ & $\begin{array}{l}- \\
-\end{array}$ & $\begin{array}{l}- \\
-\end{array}$ & - & - & - & $\begin{array}{l}1 \\
-\end{array}$ & - & ${ }^{1}-$ & $\begin{array}{l}1 \\
-\end{array}$ & $\begin{array}{l}1 \\
-\end{array}$ & - \\
\hline
\end{tabular}

